The Journal of

Thoracic and Cardiovascular

Surgery

Vol 125, No. 4, April 2003

\title{
Valve-sparing aortic root replacement in patients with the Marfan syndrome
}

D. Craig Miller, MD

See related article on page 789 .
From the Department of Cardiovascular Surgery, Stanford University School of Medicine, Stanford, Calif.

Received for publication Sept 7, 2002; revisions requested Sept 17, 2002; revisions received Sept 23, 2002; accepted for publication Oct 3, 2002.

Address for reprints: D. Craig Miller, MD, Department of Cardiovascular Surgery, Stanford University School of Medicine, Falk Cardiovascular Research Center CV 243, 300 Pasteur Dr, Stanford, CA 943055407 (E-mail: dcm@ @ stanford.edu).

J Thorac Cardiovasc Surg 2003;125:773-8

Copyright $\odot 2003$ by The American Association for Thoracic Surgery

$0022-5223 / 2003 \$ 30.00+0$

doi: $10.1067 / \mathrm{mtc} .2003 .162$

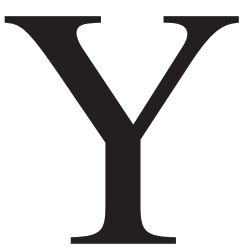

our Editor solicited commentary for this provocative article, ${ }^{1}$ not so much to enter the fray concerning which method of valvesparing aortic root replacement-Yacoub remodeling versus David reimplantation-is best for patients with the Marfan syndrome (MFS), but to clarify for the readership the key differences between the two procedures and how these operations have evolved. I will also emphasize six points raised by the article.

Historically, conventional cardiovascular surgical treatment for patients with the MFS who have aneurysm or dissection involving the ascending aorta has been replacement of the entire aortic root and valve with a composite valve graft (CVG) and reimplantation of the coronary artery ostia. A CVG incorporating a mechanical valve is usually used because most of these patients are young, can safely tolerate anticoagulation with warfarin, and do not wish to accept the risk of another operation. Over the past 30 years, CVG has become a low risk operation and a very durable one for patients with the MFS..$^{2-4}$ On the other hand, some patients have medical contraindications that make indefinite anticoagulation inadvisable, others are not medically compliant enough for anticoagulation to be safe, some individuals have lifestyles that make anticoagulation hazardous, others do not have secure long-term access to health insurance or continuing medical care, some have an aversion to anticoagulation, and the older patients do not need a new valve that will last for many decades. In these relatively infrequent circumstances, the aortic root and valve can be replaced with an allograft aortic root, a stentless porcine xenograft aortic root, or a Dacron tube graft with a stented bioprosthesis sewn into it. ${ }^{4} \mathrm{~A}$ Ross-Shumway procedure is contraindicated because of the aneurysmal disease and underlying connective tissue disorder. The durability of all these various tissue valve alternatives, however, is limited. Furthermore, the risk at reoperation is not negligible; for example, an allograft may be densely calcified, sternal re-entry may be perilous, the coronary ostia need to be reimplanted again, and the aortic annulus may have scarred down excessively. Another option gaining popularity for those wishing to avoid anticoagulation is valve-sparing aortic root replacement. But this option is also a trade-off. How many years without warfarin will the valve last before a second operation becomes necessary?

Valve-sparing aortic root replacement operations can be subdivided into two general families: (1) the Yacoub "remodeling" procedure used since 19795-9 and (2) the David "reimplantation" procedure performed since 1988. ${ }^{1,10-14}$ The paper under discussion in this issue ${ }^{1}$ of the Journal is focused solely on 105 patients with the MFS classified strictly according to the Ghent criteria: 44 patients received a CVG and 61 underwent valve-sparing aortic root replacement. What is the difference between the remodeling and the reimplantation methods of valve-sparing aortic root replacement? The easiest way to distinguish between them is whether the procedure 
employs 2 aortic suture lines (Yacoub remodeling technique) or 3 (David reimplantation technique). There are variations of the remodeling procedure, ${ }^{15-19}$ but they all rely on sewing the scalloped graft to residual aortic sinus tissue around the aortic cusps and commissures proximally. One putative advantage of the remodeling approach is that the graft billows, thereby mimicking the natural sinuses of Valsalva. This allows more natural leaflet motion ${ }^{9}$ and should theoretically reduce cusp closing stresses and thereby enhance long-term valve durability. ${ }^{20,21}$ Conversely, there are two drawbacks of any remodeling procedure: (1) absence of fixation of the aortic annulus (more properly called the "ventriculo-aortic junction," which is coronet shaped and not planar), which can predispose to postoperative annular dilatation and recurrent aortic regurgitation (AR); and (2) two (instead of one) exposed aortic suture lines, which can predispose to bleeding. Of course, both techniques require reimplantation of the coronary ostia (preferably using full-thickness Carrel buttons), which less commonly can also be sites of bleeding. When Sir Magdi discussed the current paper ${ }^{1}$ as well as David and Feindel's paper ${ }^{12}$ presented at the 2000 annual meeting of The American Association for Thoracic Surgery, he mentioned subtle modifications in his technique over the years, including picking the proper graft size, cutting narrower and shorter scallops in the graft, and reattaching the commissures up inside the graft higher than the apex of the scallops. Other adaptations include those reported by Dion's group ${ }^{17}$ in 27 patients (9 with the MFS), Svensson's semi-inclusion hybrid technique ${ }^{18}$ used in 13 patients (not stated was how many had the MFS), which relies on side-to-side anastomoses that may not necessarily be full-thickness suture bites, and Hvass' method ${ }^{19}$ wherein the lower scalloped Dacron graft is placed inside the retained native sinuses $(n=5)$. Schäfers' unit in Homburg has a relatively large overall experience $(n=99)$ predominately with the Yacoub approach, ${ }^{22-24}$ but had only 5 patients with the MFS in their latest report. ${ }^{24}$ Even more confusing, David himself also used two remodeling techniques in the past-which I call the "T. David-II" (classic Yacoub remodeling) and the "T. David-III" (remodeling with an external synthetic strip added between the left and right mitral fibrous trigones [the fibrous portion of the left ventricular outflow tract] as an external narrowing annuloplasty). ${ }^{1,12,13}$

What is the rationale behind the various modifications of the reimplantation technique and what do they strive to accomplish? Number one, all reimplantation methods firmly anchor the aortic graft proximally at the ventriculo-aortic junction below the leaflets with the commissures sewn inside the Dacron graft. Although David objects to my labeling, I have resorted to numbering his various valvesparing aortic root operations because Tirone's technique changes frequently: A "T. David-I" is his original reimplan- tation procedure using a cylindrical tube graft; the "T. David-II" and "T. David-III" are variations of Yacoub's remodeling procedure (see above); a "T. David-IV" is reimplantation using a 4-mm larger graft size with plication of the graft circumferentially at the sinotubular junction above the tops of the commissures; and a "T. David-V" (used by David and me since May 2001) is reimplantation using an even larger graft size $(\mathrm{d}+6-8 \mathrm{~mm})$, which is "necked down" at both the bottom and the top ends to create graft pseudosinuses (Figure 1). The "T. David-V" technique gives the surgeon unlimited flexibility in terms of the relative sizes that he or she makes the annulus, neosinuses, and sinotubular ridge, as well as the "height" of the neosinuses, which are quite prominent echocardiographically. Since David's entire valve-sparing experience (1988-2001) in 61 MFS patients is reported in the current article, ${ }^{1}$ one assumes that all 5 procedures were used: reimplantation in 39 ("T. David-I, -IV, or -V") and remodeling in 22 ("T. David-II or -III"). Other modifications of reimplantation valve-sparing root replacement include the Cochran procedure ${ }^{20}$ introduced in 1995 ( $\mathrm{n}=10,5$ with the MFS), which is noteworthy because it creates pseudosinuses in the graft as prompted by the mathematical modeling studies of Cochran, ${ }^{20}$ Grande-Allen, ${ }^{21}$ and their associates. An innovative modification by Mohr's group ${ }^{25}$ in 13 patients (4 with the MFS) reduces the size of the natural sinuses of Valsalva, and they are then sewn inside of graft in toto as one circular transverse suture line, instead of the usual up and down around the scalloped commissures. Moritz started in Vienna using the classic "T. David-I" technique, ${ }^{26}$ but since moving to Frankfurt he has modified the technique to use an oversized graft and plicate the bottom (or annular) end of the graft in an attempt to create neosinuses.* This is different from the "T. David-IV" procedure, in which only the distal end (or sinotubular junction) of the graft is necked down. Moritz's group demonstrated more physiologic leaflet opening and closing dynamics in 21 patients who underwent their modified David valve-sparing root replacement compared with 25 others who had a "T. David-I," but only 3 patients had the MFS.* The Hannover group, initially under the direction of Professor Hans Borst and subsequently Axel Haverich, has popularized the original "T. David-I" reimplantation concept, which they first started using in 1993. ${ }^{27-31}$ In their most recent publication of 101 patients, they analyzed 75 individuals who had been followed up for longer than 1 year; of these, 22 had the MFS. ${ }^{28}$ MFS was not a predictor of postoperative AR. Recently, De Paulis and associates ${ }^{32,33}$ introduced a new "sinus graft" that includes a larger size, compliant graft segment ("skirt") above a narrower, short "collar"; De Paulis's group ${ }^{34}$ originally used

*Aybek T, Wöhleke T, Sotiriou M, Miskovic A, Simon A, Doss M, et al. Alteration of opening and closing cusp dynamics after aortic valve sparing operations. Unpublished data. 

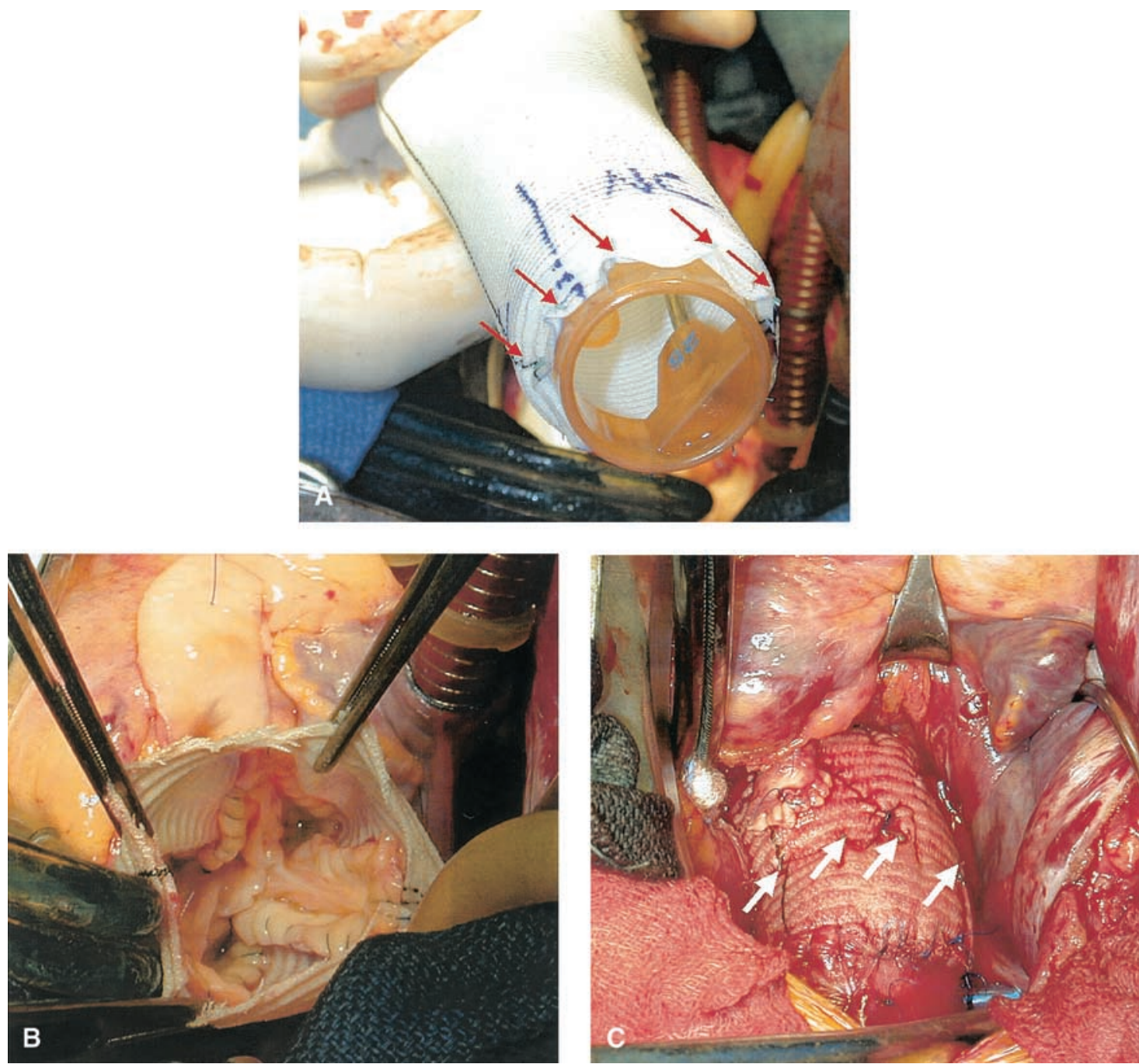

Figure 1. A, Operative photograph of "T. David-V" reimplantation valve-sparing aortic root replacement in a patient with the MFS illustrating how the over-sized 32-mm woven double velour Hemashield graft (Medi-Tech, Boston Scientific Corp, Natick, Mass) is necked down proximally to fit a 25-mm valve sizer using interrupted 5-0 plication sutures (red arrows). B, The valve is sewn inside the graft before the distal end of the graft is plicated. Using a larger graft facilitates exposure and eliminates buckling and crowding of the aortic root tissue when sewing the scalloped upper valve suture line compared with when a smaller, cylindrical tube graft is used, as in the "T. David-I" procedure. C, Completed operation showing the reimplanted right coronary artery button and interrupted 5-0 braided polyester plication sutures (some of which are denoted by the white arrows) at the top of the commissures to neck down the sinotubular junction of the graft.

this graft for Yacoub remodeling but soon switched to the David reimplantation method; 5 of their 16 patients had the MFS. Changing to the reimplantation technique is not surprising given that an earlier paper on Yacoub remodeling from this same unit ${ }^{35}(\mathrm{n}=36,4$ with the MFS) reported that 3 of 4 patients with the MFS had required reoperation within 3 years. This newly available commercial graft is an attractive concept. Modifying the fabrication of the graft using customized teardrop-shaped sinuses of individual compliance was devised by Thubrikar and Robicsek ${ }^{36-38}$ and can be applied either to remodeling or to reimplantation.

Over the past decade, some surgeons, Tirone David and I included, switched temporarily to the Yacoub remodeling technique because it is quicker, saves one suture line, and requires much less extensive dissection and mobilization of the aortic root; however, most of us soon recognized that it was not as predictable as the reimplantation technique, especially in patients with the MFS. On the other hand, rare 
patients have the aortic annulus so deeply "countersunk" that adequate mobilization of the base of the aortic root to place the bottom row of sutures in the subannular plane for valve reimplantation may require skeletonization of the tricuspid annulus and the central fibrous body of the heart; in such circumstances, reverting either to a remodeling procedure or a CVG is prudent. Patients with an extremely dilated aortic annulus ( $\geq 29-31 \mathrm{~mm}$ ) and/or abnormal aortic leaflets should probably receive a CVG because one cannot be confident about long-term valve durability. On the other hand, individuals with prolapse (usually the noncoronary cusp) or with stretched, elongated aortic valve cusps can have successful repair by reducing the length of the cusp free margin with a 5-0 or 6-0 braided polyester plication suture, which elevates the level of cusp coaptation higher up into the graft. ${ }^{4,24}$ David uses a running 6-0 polytetrafluoroethylene* suture for this step. Indeed, one actually creates relative prolapse de facto in making the aortic root considerably smaller using either technique, which underscores not selecting too small a graft. Haverich's group has recently pointed out the importance of recreating a higher plane of cusp coaptation to enhance valve competence. ${ }^{28}$

As surgeons have gained more experience, valve-sparing aortic root replacement has been applied to other patient substrates, including those with bicuspid aortic valves, ${ }^{1,7,22}$ acute type A aortic dissection, 1,7,23,27,39,40 a failing (full root) Ross procedure secondary to dilatation of the sinotubular junction, ${ }^{41,42}$ and patients with a chronic type A dissection after previous supracoronary tube graft repair. ${ }^{31}$ While the short-term results using either remodeling $7,23,39$ or reimplantation $^{1,27}$ for acute aortic dissection have generally been satisfactory in terms of valve durability, long-term survival has not been optimal. ${ }^{7}$ The Hannover group, however, recently cautioned that 3 of 8 patients with acute dissection who received a Yacoub remodeling procedure required reoperation for AR within 4 years. ${ }^{40}$ The David reimplantation concept is better for acute aortic dissection because it is more hemostatic - the only suture lines that can bleed are the coronary buttons and the distal aortic anastomosis. In fact, David's current article states that the take-back for bleeding rates was $3 \%$ for reimplantation versus $18 \%$ for remodeling in patients with the MFS (and only $15 \%$ of these patients had an acute aortic dissection) ${ }^{1}$

\section{Issues in the Current Article}

This article ${ }^{1}$ deserves amplification regarding six points. First, it is remarkable that no patient having a valve-sparing procedure required reoperation for AR in the absence of endocarditis. The 8-year results after valve reimplantation are excellent, despite the theoretical shortcoming that no graft pseudosinuses were created in their earlier ("T. David-

*Gore-Tex suture; registered trade mark of W. L. Gore \& Associates, Inc, Flagstaff, Ariz.
I") experience. ${ }^{1,29,30}$ Second, only the reimplantation procedure has been performed in MFS patients by this group since 1999. This change is probably based on both practical considerations (more bleeding with the Yacoub procedure) and long-term concerns about valve durability after remodeling. Third, the comparisons between the valve-sparing and the CVG groups should be interpreted with circumspection, as the CVG group was quite different and had longer follow-up. Fourth, 18 of the 44 CVG patients had biologic valves used, and 3 of these tissue valves ultimately failed and necessitated reoperation; thus, the actuarial curves in the graphs depicting freedom from reoperation or valverelated morbidity and mortality are exaggerated. The authors do, however, report in the text the freedom rates for CVG patients who received a mechanical valve, which are higher. Fifth, while it is apparent that the MFS patients who underwent a Yacoub-type of valve-sparing aortic root replacement experienced over time a 5\% increase in aortic annulus diameter and 17\% increase in neo-aortic sinus diameter (see Table 3), this was due to progressive dilatation in only 10 of the 22 patients who underwent remodeling. ${ }^{1}$ Annuloplasty ("T. David-III") had no demonstrable effect on late dilatation. Why did some Yacoub patients have dilatation and others not? Was this a function of the initial annular or aneurysm size? Did it have anything to do with individual pathologic conditions, for example, acute aortic dissection? It will take analysis of larger numbers of patients to answer these questions, but such insight could lead to more refined criteria for specifically when to avoid a remodeling procedure. Sixth, children were excluded from this report (with the exception of one 12-year-old boy) because pediatric patients are not operated on at the Toronto General Hospital. ${ }^{1}$ Treating children with the MFS and ascending aortic disease introduces a whole different set of problems. Even though an adult-sized CVG can usually be used in a child over the age of 10 years, indefinite anticoagulation during the adolescent years is challenging and not without complications. Allograft aortic root replacement has been discouraging because of very limited durability, but in younger children a David-type of reimplantation valve-sparing procedure may result in the child outgrowing the (fixed) aortic annulus and requiring reoperation for stenosis. In an attempt to find something superior to the use of allografts, Cameron has performed 80 valve-sparing aortic root replacements at Johns Hopkins; approximately 40 of which were in children or young adults (about one-half of these had the MFS). Only one of the MFS patients has required reoperation so far, but worrisome annular dilatation and AR have developed postoperatively in many patients (personal communication, Duke E. Cameron, MD, 2002). Unsatisfactory results with the Yacoub procedure in children have also been reported from the Hôpital NeckerEnfants in Paris. ${ }^{43}$ 


\section{The Bottom Line}

We now know that either type of valve-sparing aortic root replacement is safe, reproducible, and associated with reasonable 5- to 10-year results for selected patients with the MFS, at least in certain institutions. While satisfactory, the outcomes are not perfect. Notwithstanding the excellent survival statistics in the current report, $25 \%$ of the MFS patients undergoing valve-sparing aortic root replacement had $3+$ or $4+$ AR at 10 years (Figure 4$)^{1}$; further, inspection of Figure 5 suggests that the late actuarial estimate of freedom from AR was lower (albeit insignificantly so due to the small numbers of patients remaining at risk) if the Yacoub technique was used $(71 \% \pm 21 \%$ free for remodeling versus $96 \% \pm 4 \%$ for reimplantation at 8 years). The latest report (average follow-up 36 months) from the Hannover group ${ }^{28}$ reported that 8 of 75 patients $(22$ had the MFS) had $2+$ or more AR beyond 1 year, and 3 had already required reoperation. In Yacoub's experience using exclusively the remodeling technique in 82 patients with the MFS, $17 \%$ had required reoperation by 10 years, and an additional $22 \%$ had moderate AR at the time of last follow-up (mean $=5.5$ years, median $=3$ years). ${ }^{8}$

What remains unknown is the truly long-term results in larger numbers of patients with the MFS and whether the overall incidence of all valve-related and aorta-related complications will be lower than that after conventional CVG with a mechanical prosthetic valve. To this end, the National Marfan's Foundation is sponsoring a prospective multicenter registry investigation of both types of valvesparing aortic root replacement procedures in patients with the MFS. Participating centers from around the world have already committed to this project, which they hope will be launched in 2003. Clinical and operative information, as well as serial echocardiographic, computed tomographic, and magnetic resonance imaging data, will be collected and analyzed. Only when the long-term results of such studies are compiled will we know with certainty which type of valve-sparing operation is more durable, how "generalizable" the clinical results really are, and whether overall outcome is superior to that after CVG.

In the interim, with all due respect to Sir Magdi's beliefs and vast experience (he truly is a master surgeon), I believe we should be conservative for valve-sparing aortic root replacement in patients with the MFS, which is the most demanding patient substrate: a reimplantation-type procedure that reliably prevents future dilatation of the aortic annulus is the most prudent choice based on the data available at this time. Seasoned surgical judgment and careful patient selection are key in deciding whether valve-sparing root replacement is the best option. It also is implicit that a patient who chooses valve-sparing root replacement be well informed and understand that a second operation may be necessary. Patients should seek out a cardiovascular sur- geon who has considerable personal experience with valvesparing aortic root replacement, because the initial learning curve can be steep. These procedures are unforgiving in terms of small technical errors and, at this time, truly are based more on 3-dimensional geometric thinking and "art" than they are on science.

\section{References}

1. de Oliveira NC, David TE, Ivanov J, Armstrong S, Eriksson MJ, Rakowski H, et al. Results of surgery for aortic root aneurysm in patients with Marfan syndrome. J Thorac Cardiovasc Surg. 2003;125: 789-96.

2. Gott VL, Greene PS, Alejo DE, Cameron DE, Naftel DC, Miller DC, et al. Replacement of the aortic root in patients with Marfan's syndrome. N Engl J Med. 1999;340:1307-13.

3. Yun KL, Miller DC, Fann JI, Mitchell RS, Robbins RC, Moore KA, et al. Composite valve graft versus separate aortic valve and ascending aortic replacement-Is there still a role for the separate procedure? Circulation. 1997;96(Suppl):II-368-75.

4. Miller DC. Valve-sparing aortic root replacement in the Marfan syndrome: an update. National Marfans Foundation Connective Issues. Fall 2001. http://www.marfan.org/pub/newsletter/vol21-1/07.html.

5. Yacoub M, Fagan A, Stassano P, Radley-Smith R. Results of valve conserving operations for aortic regurgitation [abstract]. Circulation 1983;68(Suppl):III-321.

6. Sarsam MAI, Yacoub M. Remodeling of the aortic valve anulus. J Thorac Cardiovasc Surg. 1993;105:435-8.

7. Yacoub MH, Gehle P, Chandrasekaran V, Birks EJ, Child A, RadleySmith R. Late results of a valve-preserving operation in patients with aneurysms of the ascending aorta and root. J Thorac Cardiovasc Surg. 1998; 115:1080-90.

8. Birks EJ, Webb C, Child A, Radley-Smith R, Yacoub MH. Early and long-term results of a valve-sparing operation for Marfan syndrome. Circulation. 1999;100(Suppl):II-29-35.

9. Leyh RG, Schmidtke C, Sievers H-H, Yacoub MH. Opening and closing characteristics of the aortic valve after different types of valve-preserving surgery. Circulation. 1999;100:2153-60.

10. David TE, Feindel CM. An aortic valve-sparing operation for patients with aortic incompetence and aneurysm of the ascending Aorta. J Thorac Cardiovasc Surg. 1992;103:617-21.

11. Tambeur L, David TE, Unger M, Armstrong S, Ivanov J, Webb G. Results of surgery for aortic root aneurysm in patients with the Marfan syndrome. Eur J Cardio-Thorac Surg. 2000;17:415-9.

12. David TE, Armstrong S, Ivanov J, Feindel CM, Omran A, Webb G. Results of aortic valve-sparing operations. J Thorac Cardiovasc Surg. 2001;122:39-46.

13. David TE, Armstrong S, Ivanov J, Webb GD. Aortic valve sparing operations: an update. Ann Thorac Surg. 1999;67:1840-2.

14. David TE, Feindel CM, Bos J. Repair of the aortic valve in patients with aortic insufficiency and aortic root aneurysm. $J$ Thorac Cardiovasc Surg. 1995;109:345-52.

15. Schäfers H-J, Fries R, Langer F, Nikoloudakis N, Graeter T, Grundmann U. Valve-preserving replacement of the ascending aorta: remodeling versus reimplantation. J Thorac Cardiovasc Surg. 1998;116: 990-6.

16. Luciani GB, Casali G, Tomezzoli A, Mazzucco A. Recurrence of aortic insufficiency after aortic root remodeling with valve preservation. Ann Thorac Surg. 1999;67:1849-52.

17. El Khoury GA, Underwood MJ, Glineur D, Derouck D, Dion RA. Reconstruction of the ascending aorta and aortic root: experience in 45 consecutive Patients. Ann Thorac Surg. 2000;70:1246-50.

18. Svensson LG, Longoria J, Kimmel WA, Nadolny E. Management of aortic valve disease during aortic surgery. Ann Thorac Surg. 2000;69: 778-84.

19. Hvass U. A new technique for sparing the aortic valve in patients with aneurysm of the ascending aorta and root. J Thorac Cardiovasc Surg. 2000;119:1048-9. 
20. Cochran RP, Kunzelman KS, Eddy AC, Hofer BO, Verrier ED. Modified conduit preparation creates a pseudosinus in an aortic valvesparing procedure for aneurysm of the ascending aorta. $J$ Thorac Cardiovasc Surg. 1995;109:1049-58.

21. Grande-Allen KJ, Cochran RP, Reinhall PG, Kunzelman KS. Recreation of sinuses is important for sparing the aortic valve: a finite element study. J Thorac Cardiovasc Surg. 2000;119:753-63.

22. Schäfers H-J, Langer F, Aicher D, Graeter TP, Wendler O. Remodeling of the aortic root and reconstruction of the bicuspid aortic valve. Ann Thorac Surg. 2000;70:542-6.

23. Graeter TP, Langer F, Nikoloudakis N, Aicher D, Schäfers H-J. Valve-preserving operation in acute aortic dissection type A. Ann Thorac Surg. 2000;70:1460-5.

24. Langer F, Graeter T, Nikoloudakis N, Aicher D, Wendler O, Schäfers H-J. Valve-preserving aortic replacement: Does the additional repair of leaflet prolapse adversely affect the results? J Thorac Cardiovasc Surg. 2001;122:270-7.

25. van Son JAM, Battellini R, Mierzwa M, Walther T, Autschbach R, Mohr FW. Aortic root reconstruction with preservation of native aortic valve and sinuses in aortic root dilatation with aortic regurgitation. J Thorac Cardiovasc Surg. 1999;117:1151-6.

26. Simon P, Moritz A, Moidl R, Kupilik N, Grabenwöger M, Ehrlich M, et al. Aortic valve resuspension in ascending aortic aneurysm repair with aortic insufficiency. Ann Thorac Surg. 1995;60:176-80.

27. Kallenbach K, Pethig K, Leyh RG, Baric D, Haverich A, Harringer W. Acute dissection of the ascending aorta: first results of emergency valve sparing aortic root reconstruction. Eur J Cardio-Thorac Surg. 2002;22:218-22.

28. Pethig K, Milz A, Hagl C, Harringer W, Haverich A. Aortic valve reimplantation in ascending aortic aneurysm: risk factors for early failure. Ann Thorac Surg. 2002;73:29-33.

29. Kallenbach K, Pethig K, Schwarz M, Milz A, Haverich A, Harringer W. Valve sparing aortic root reconstruction versus composite replacement-perioperative course and early complications. Eur J CardioThorac Surg. 2001;20:77-81.

30. Harringer W, Pethig K, Hagl C, Meyer GP, Haverich A. Ascending aortic replacement with aortic valve reimplantation. Circulation. 1999;100(Suppl):II-24-8.

31. Leyh RG, Fischer S, Ruhparwar A, Karck M, Harringer W, Haverich A. Valve-sparing aortic root replacement in patients after a previous operation for acute type A aortic dissection. J Thorac Cardiovasc Surg. 2002;123:377-8.
32. De Paulis R, De Matteis GM, Nardi P, Scaffa R, Buratta M, Chiariello L. Opening and closing characteristics of the aortic valve after valvesparing procedures using a new aortic root conduit. Ann Thorac Surg. 2001;72:487-94.

33. De Paulis R, De Matteis GM, Nardi P, Scaffa R, Bassano C, Chiariello L. Analysis of valve motion after reimplantation type of valve-sparing procedure (David-I) with a new aortic root conduit. Ann Thorac Surg. 2002;74:53-7.

34. De Paulis R, De Matteis GM, Nardi P, Scaffa R, Colella DF, Bassano $\mathrm{C}$, et al. One-year appraisal of a new aortic root conduit with sinuses of Valsalva. J Thorac Cardiovasc Surg. 2002;123:33-9.

35. Bassano C, De Matteis GM, Nardi P, Buratta MM, Zeitani J, De Paulis $\mathrm{R}$, et al. Mid-term follow-up of aortic root remodelling compared to the Bentall operation. Eur J Cardio-Thorac Surg. 2001;19:601-5.

36. Thubrikar MJ, Robicsek F, Gong GG, Fowler BL. A new aortic root prosthesis with compliant sinuses for valve-sparing operations. Ann Thorac Surg. 2001;71:S318-22.

37. Robicsek F, Thubrikar MJ, Fokin AA. Cause of degenerative disease of the trileaflet aortic valve: review of subject and presentation of a new theory. Ann Thorac Surg. 2002;73;1346-54.

38. Zehr KJ, Thubrikar MJ, Gong GG, Headrick JR, Robicsek F. Clinical introduction of a novel prosthesis for valve-preserving aortic root reconstruction for annuloaortic ectasia. $J$ Thorac Cardiovasc Surg. 2000;120:692-8.

39. Leyh RG, Schmidtke C, Bartels C, Sievers H-H. Valve-sparing aortic root replacement (remodeling/reimplantation) in acute type A dissection. Ann Thorac Surg. 2000;70;21-4.

40. Leyh RG, Fischer S, Kallenbach K, Kofidis T, Pethig K, Harringer W, et al. High failure rate after valve-sparing aortic root replacement using the "remodeling technique" in acute type A aortic dissection. Circulation. 2002;106(Suppl):I-229-33.

41. Sundt TM, Moon MR, Xu H. Reoperation for dilatation of the pulmonary artery autograft after the Ross procedure. $J$ Thorac Cardiovasc Surg. 2001;122:1249-52.

42. Schmidtke C, Stierle U, Sievers H-H. Valve-sparing aortic root remodeling for pulmonary autograft aneurysm. J Heart Valve Dis. 2002;11:504-5

43. Massih TA, Vouhé PR, Mauriat P, Mousseaus E, Sidi D, Bonnet D. Replacement of the ascending aorta in children: a series of fourteen patients. J Thorac Cardiovasc Surg. 2002;124:411-3. 